\title{
Catalytic properties of wheat phytase that favorably degrades long-chain inorganic polyphosphate
}

\author{
Jeongmin $\mathrm{An}^{1}$ and Jaiesoon $\mathrm{Cho}^{1, *}$
}

* Corresponding Author: Jaiesoon Cho Tel: +82-2-450-3375, Fax: +82-2-455-1044, E-mail: chojs70@konkuk.ac.kr

'Department of Animal Science and Technology, Konkuk University, Seoul 05029, Korea

\section{ORCID}

Jeongmin An

https://orcid.org/0000-0002-2357-0941 Jaiesoon Cho

https://orcid.org/0000-0002-4511-8032

Submitted Jan 16, 2019; Revised Apr 4, 2019; Accepted Apr 29, 2019
Objective: This study was conducted to determine catalytic properties of wheat phytase with exopolyphosphatase activity toward medium-chain and long-chain inorganic polyphosphate (polyP) substrates for comparative purpose.

Methods: Exopolyphosphatase assay of wheat phytase toward polyP75 (medium-chain polyP with average 75 phosphate residues) and polyP1150 (long-chain polyP with average 1150 phosphate residues) was performed at $\mathrm{pH} 5.2$ and $\mathrm{pH} 7.5$. Its activity toward these substrates was investigated in the presence of $\mathrm{Mg}^{2+}, \mathrm{Ni}^{2+}, \mathrm{Co}^{2+}, \mathrm{Mn}^{2+}$, or ethylenediaminetetraacetic acid (EDTA). Michaelis constant $\left(\mathrm{K}_{\mathrm{m}}\right)$ and maximum reaction velocity $\left(\mathrm{V}_{\max }\right)$ were determined from Lineweaver-Burk plot with polyP75 or polyP1150. Monophosphate esterase activity toward $p$-nitrophenyl phosphate ( $p \mathrm{NPP}$ ) was assayed in the presence of polyP75 or polyP1150. Results: Wheat phytase dephosphorylated polyP75 and polyP1150 at pH 7.5 more effectively than that at $\mathrm{pH}$ 5.2. Its exopolyphosphatase activity toward polyP75 at pH 5.2 was 1.4-fold higher than that toward polyP1150 whereas its activity toward polyP75 at pH 7.5 was 1.4-fold lower than that toward polyP1150. Regarding enzyme kinetics, $\mathrm{K}_{\mathrm{m}}$ for polyP75 was 1.4-fold lower than that for polyP1150 while $\mathrm{V}_{\max }$ for polyP1150 was 2-fold higher than that for polyP75. The presence of $\mathrm{Mg}^{2+}, \mathrm{Ni}^{2+}, \mathrm{Co}^{2+}, \mathrm{Mn}^{2+}$, or EDTA (1 or $5 \mathrm{mM}$ ) exhibited no inhibitory effect on its activity toward polyP75. Its activity toward polyP1150 was inhibited by $1 \mathrm{mM}$ of $\mathrm{Ni}^{2+}$ or $\mathrm{Co}^{2+}$ and $5 \mathrm{mM}$ of $\mathrm{Ni}^{2+}, \mathrm{Co}^{2+}$, or $\mathrm{Mg}^{2+}$. $\mathrm{Ni}^{2+}$ inhibited its activity toward polyP1150 the most strongly among tested additives. Both polyP75 and polyP1150 inhibited the monophosphate esterase activity of wheat phytase toward $p \mathrm{NPP}$ in a dose-dependent manner.

Conclusion: Wheat phytase with an unexpected exopolyphosphatase activity has potential as a therapeutic tool and a next-generational feed additive for controlling long-chain polyPinduced inappropriate inflammation from Campylobacter jejuni and Salmonella typhimurium infection in public health and animal husbandry.

Keywords: Animal Husbandry; Exopolyphosphatase; Inflammation; Inorganic Polyphosphate; Public Health; Wheat Phytase

\section{INTRODUCTION}

Inorganic polyphosphate (polyP) is a highly negative-charged linear polymer with three to over a thousand ortho-phosphate $(\mathrm{Pi})$ residues connected by phosphoanhydride bonds like high-energy phosphate compound adenosine 5 '-triphosphate [1,2]. It has been reported to be detectable in nearly all biological systems [2]. As a representative example, medium-chain polyP with about 60 to $100 \mathrm{Pi}$ units long has been found in human platelets while long-chain polyP with thousands of Pi units long exists exclusively in infectious microorganisms [2]. In eukaryotes, polyP covers various physiological roles such as bone mineralization, cell proliferation, tumor metastasis, blood clotting and inflammation [1]. However, important roles of polyP in bacteria are concentrated on the expression of pathogenesis [3,4]. In this 
regard, Campylobacter jejuni and Salmonella typhimurium are main bacterial pathogens of foodborne gastroenteritis in human all over the world $[3,4]$. They are closely associated with poultry and its products such as egg, meat, and processed carcass [5-7]. Furthermore, Campylobacter jejuni and Salmonella typhimurium are ubiquitous in poultry, cattle, swine and sheep, resulting in substantial foodborne illnesses [8]. Indeed, various biological tools that directly or indirectly inactivate these bacteria within the host have been used to decrease the outbreaks of foodborne pathogens in poultry and livestock [8]. Interestingly, Campylobacter jejuni and Salmonella typhimurium operate well-established polyP metabolic pathways in which polyP pools are principally regulated by exopolyphosphatase hydrolyzing polyP to inorganic phosphate $[3,4,9]$. Moreover, degradation of polyP can lead to decreased production of their virulent elements and infectious performances in host $[3,4]$.

Today, microbial phytase is one of representative feed enzymes widely employed in animal husbandry [10]. It exclusively catalyzes the release of inorganic phosphate from phytate (inositol-hexakisphosphate, Ins $\mathrm{P}_{6}$ ) as its main substrate that is rich in cereals, oilseeds, and legumes [10]. Phytate acts as antinutritional agent in mono-gastric animals such as swine and poultry, further generating environmental phosphorus pollution [10]. Intriguingly, wheat phytase is an unusual phytate-degrading enzyme categorized into multiple inositol polyphosphate phosphatase that can non-specifically dephosphorylate $p$-nitrophenyl phosphate ( $p \mathrm{NPP}$ ) and 2,3-bisphosphoglycerate as well as more phosphorylated diphospho-myo-inositol pentakisphosphate (PP-InsP $\mathrm{P}_{5}$ ) and bisdiphospho-myo-inositol tetrakisphosphate $\left([\mathrm{PP}]_{2}-\mathrm{InsP}_{4}\right)[11,12]$. Thus, wheat phytase might be able to catalyze the hydrolysis of polyP. The objective of this study was to determine catalytic properties of wheat phytase with exopolyphosphatase activity toward mediumchain and long-chain polyP substrates for comparative purpose. To the best of our knowledge, this is the first report about such properties of wheat phytase.

\section{MATERIALS AND METHODS}

\section{Substrates and preparation of enzyme}

Medium-chain polyP (polyP75) with average $75 \mathrm{Pi}$ units long and long-chain polyP (polyP1150) with average 1150 Pi units long were purchased from Kerafast (Boston, MA, USA). The $p$ NPP was obtained from Sigma-Aldrich (St. Louis, MO, USA).

Wheat phytase (Sigma-Aldrich, USA) was reconstituted in endotoxin-free water (Sigma-Aldrich, USA). The enzyme was then dialyzed against $50 \mathrm{mM}$ Tris- $\mathrm{HCl}(\mathrm{pH} 8.0)$ at $4^{\circ} \mathrm{C}$ overnight. Its inorganic phosphate background was removed by using Pi-bond resin (Innova Biosciences, Cambridge, UK) according to the manufacturer's instructions.

\section{Dephosphorylation of inorganic polyphosphates at} specific pH

Exopolyphosphatase assay was performed at $37^{\circ} \mathrm{C}$ for $20 \mathrm{~min}$ in $1 \mathrm{~mL}$ reaction mixture consisting of $20 \mu \mathrm{L}$ enzyme, $8 \mu \mathrm{M}$ polyP75 or polyP1150, and $50 \mathrm{mM} \mathrm{Na}$-acetate (pH 5.2) or Tris-HCl ( $\mathrm{pH}$ 7.5). Inorganic phosphate release was measured at optical density (OD) $635 \mathrm{~nm}$ using a malachite green-based PiColor Lock gold phosphate detection kit (Innova Biosciences, USA) according to the manufacturer's instructions.

\section{Effect of additives on exopolyphosphatase activity}

Exopolyphosphatase activity was determined at $37^{\circ} \mathrm{C}$ for 20 min in $1 \mathrm{~mL}$ reaction mixture consisting of $20 \mu \mathrm{L}$ enzyme, 8 $\mu \mathrm{M}$ polyP75 or polyP1150, and $50 \mathrm{mM}$ Tris- $\mathrm{HCl}(\mathrm{pH} 7.5)$ in the presence of 1 or $5 \mathrm{mM}$ of each additive $\left(\mathrm{Mg}^{2+}, \mathrm{Ni}^{2+}, \mathrm{Co}^{2+}\right.$, $\mathrm{Mn}^{2+}$, and ethylenediaminetetraacetic acid [EDTA]). Inorganic phosphate release was measured at OD $635 \mathrm{~nm}$ using the malachite green-based PiColor Lock gold phosphate detection kit (Innova Biosciences, USA) according to the manufacturer's instructions.

\section{Evaluation of enzyme kinetics for exopolyphosphatase activity} Kinetic parameters such as Michaelis constant $\left(\mathrm{K}_{\mathrm{m}}\right)$ and maximum reaction velocity $\left(\mathrm{V}_{\max }\right)$ for exopolyphosphatase activity were determined from Lineweaver-Burk plot with different concentrations of polyP75 or polyP1150 (8 to $26 \mu \mathrm{M})$ at pH 7.5 and $37^{\circ} \mathrm{C}$.

Effect of inorganic polyphosphates on monophosphate esterase activity

Monophosphate esterase activity was assayed at $37^{\circ} \mathrm{C}$ for 10 min in $0.6 \mathrm{~mL}$ reaction mixture containing $20 \mu \mathrm{L}$ enzyme, $0.25 \mathrm{mM} p \mathrm{NPP}$, and $50 \mathrm{mM} \mathrm{Na}$-acetate ( $\mathrm{pH}$ 5.2) in the presence of polyP75 or polyP1150 ( 0.01 to $2 \mathrm{mM})$. The reaction was quenched by adding $0.6 \mathrm{~mL}$ of $0.5 \mathrm{M} \mathrm{NaOH}$. Then $p$ nitrophenol release was measured at OD $405 \mathrm{~nm}$.

\section{Statistical analysis}

Statistical analysis was performed by one-way analysis of variance using PROC general linear model (SAS 9.4, SAS Institute Inc, Cary, NC, USA) to test for significant differences between treatments with the Duncan's multiple range test. The probability levels used for statistical significance were $p<0.05$. The results were presented as the mean and standard error from three experiments $(n=3)$.

\section{RESULTS}

\section{Exopolyphosphatase activity of wheat phytase at specific $\mathrm{pH}$}

As shown in Figure 1, wheat phytase could dephosphory- 


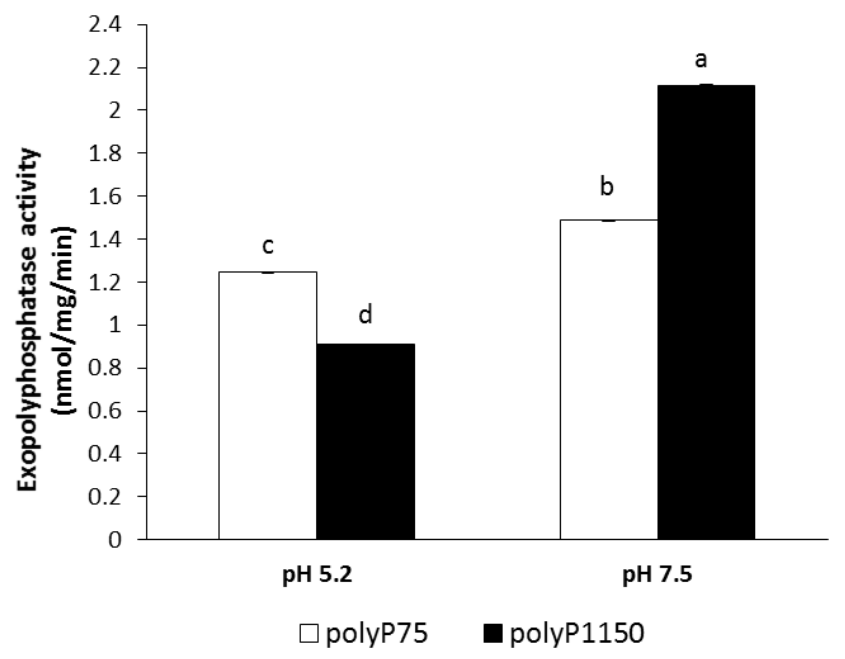

Figure 1. Exopolyphosphatase activity of wheat phytase toward polyP75 and polyP1150 at specific pH. Data were expressed as the mean and standard error from three experiments. PolyP, polyphosphate. ${ }^{\mathrm{a}-\mathrm{d}}$ Means with different superscripts differ $(p<0.05)$.

late polyP75 and polyP1150 at pH 7.5 more effectively than that at $\mathrm{pH}$ 5.2. In addition, its exopolyphosphatase activity toward polyP75 at $\mathrm{pH} 5.2$ was 1.4-fold higher than that toward polyP1150 whereas its activity toward polyP75 at pH 7.5 was 1.4 -fold lower than that toward polyP1150.

\section{Determination of kinetic parameters for} exopolyphosphatase activity

Data on enzyme kinetics for exopolyphosphatase activity of wheat phytase were presented in Table 1 . The value of $\mathrm{K}_{\mathrm{m}}$ for polyP75 was 1.4 -fold lower than that for polyP1150. Thus, the enzyme showed better substrate affinity against polyP75. Meanwhile, the value of $\mathrm{V}_{\max }$ for polyP1150 was 2-fold higher than that for polyP75.

\section{Effect of additives on exopolyphosphatase activity}

As shown in Figure 2, the presence of $\mathrm{Mg}^{2+}, \mathrm{Ni}^{2+}, \mathrm{Co}^{2+}, \mathrm{Mn}^{2+}$, or EDTA ( 1 and $5 \mathrm{mM}$ ) almost exhibited no inhibitory effect on the exopolyphosphatase activity of wheat phytase toward polyP75. However, the exopolyphosphatase activity toward polyP1150 was inhibited by $1 \mathrm{mM}$ of $\mathrm{Ni}^{2+}$ or $\mathrm{Co}^{2+}$ (Figure 3 ). Its activity was also inhibited by $5 \mathrm{mM}$ of $\mathrm{Ni}^{2+}, \mathrm{Co}^{2+}$, or $\mathrm{Mg}^{2+}$ (Figure 3). Particularly, $\mathrm{Ni}^{2+}$ at $1 \mathrm{mM}$ and $5 \mathrm{mM}$ most strongly inhibited its exopolyphophatase activity toward polyP1150,

Table 1. Kinetic parameters for exopolyphosphatase activity of wheat phytase

\begin{tabular}{lcc}
\hline Substrates & $\mathrm{K}_{\mathrm{m}}(\mu \mathrm{M})$ & $\mathbf{V}_{\max }(\mathrm{nmol} / \mathrm{mg} / \mathrm{min})$ \\
\hline polyP75 & $50.86 \pm 3.86^{\mathrm{b}}$ & $9.99 \pm 0.54^{\mathrm{b}}$ \\
polyP1150 & $69.77 \pm 1.05^{\mathrm{a}}$ & $20.08 \pm 0.21^{\mathrm{a}}$ \\
\hline
\end{tabular}

Values were expressed as the mean and standard error from three experiments. $\mathrm{K}_{\mathrm{m}}$, Michaelis constant; $\mathrm{V}_{\max }$ maximum reaction velocity; PolyP, polyphosphate.

$a, b$ Means with different superscripts within column differ $(p<0.05)$.

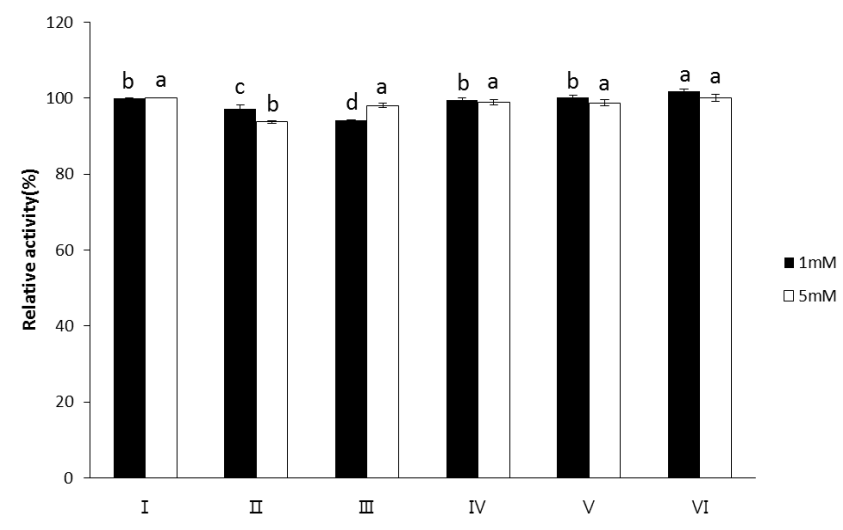

Figure 2. Effect of additives ( $1 \mathrm{mM}$ or $5 \mathrm{mM}$ ) on dephosphorylation of polyP75 by wheat phytase. I: No additive, II: $\mathrm{Mn}^{2+}, \mathrm{III}^{\mathrm{Ni}^{2+}}, \mathrm{IV}: \mathrm{Mg}^{2+}, \mathrm{V}: \mathrm{Co}^{2+}, \mathrm{VI}$ : ethylenediaminetetraacetic acid. Data were presented as the mean and standard error from three experiments. PolyP, polyphosphate. ${ }^{\text {a-d }}$ Means lacking common superscripts within each concentration differ $(p<0.05)$.

leading to $32 \%$ and $41 \%$ loss of its activity, respectively (Figure 3).

Effect of inorganic polyphosphates on monophosphate esterase activity

Both polyP75 and polyP1150 inhibited the monophosphate esterase activity of wheat phytase toward $p$ NPP (Figures 4, 5). Furthermore, at the lowest concentration of $0.01 \mathrm{mM}$, polyP75 and polyP 1150 decreased its activity by $35 \%$ and $61 \%$, respectively. At $2 \mathrm{mM}$, they resulted in $90 \%$ loss of its activities (Figures 4, 5).

\section{DISCUSSION}

In the present study, catalytic properties of wheat phytase for dephosphorylating long-chain polyP (polyP1150) and medium-chain polyP (polyP75) were described. This study reports novel and significant finding. Up to date, very limited infor-

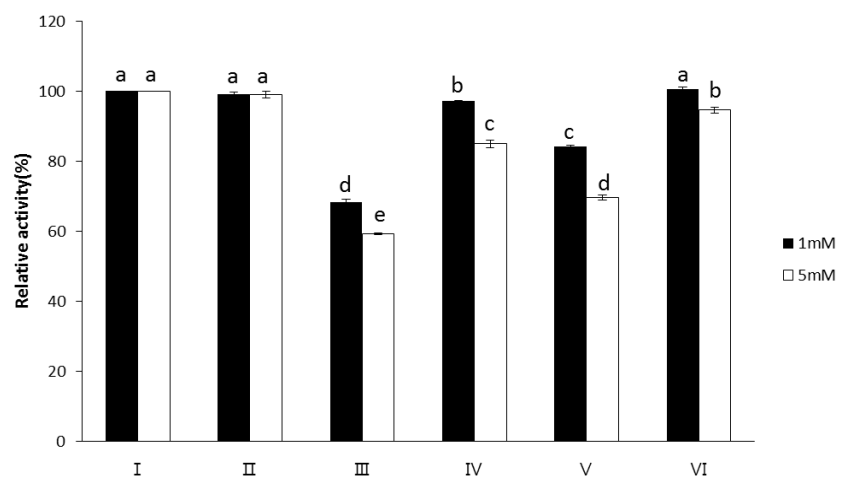

Figure 3. Effect of additives ( $1 \mathrm{mM}$ or $5 \mathrm{mM}$ ) on dephosphorylation of polyP1150 by wheat phytase. I: No additive, II: $\mathrm{Mn}^{2+}, \mathrm{III}: \mathrm{Ni}^{2+}, \mathrm{IV}^{\mathrm{Mg}^{2+}}, \mathrm{V}: \mathrm{Co}^{2+}$ VI: ethylenediaminetetraacetic acid. Data were presented as the mean and standard error from three experiments. PolyP, polyphosphate. ${ }^{\text {a-e }}$ Means lacking common superscripts within each concentration differ $(p<0.05)$. 


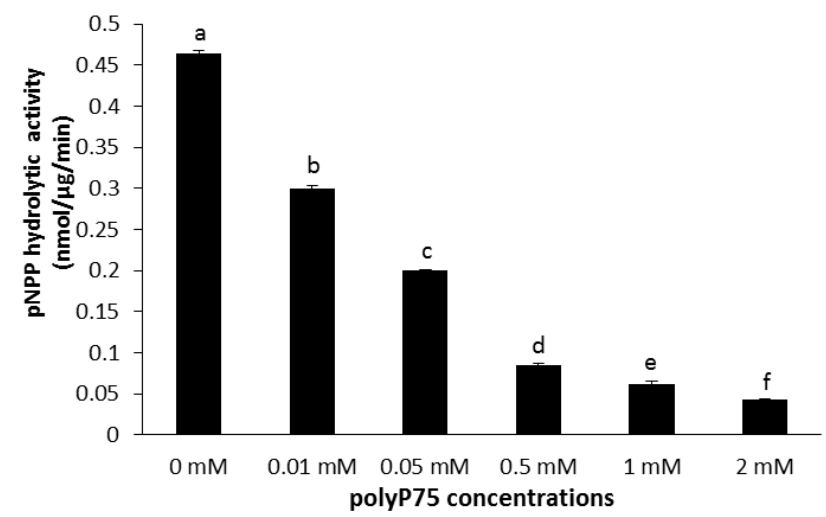

Figure 4. Effect of polyP75 on monophosphate esterase activity of wheat phytase toward p-nitrophenyl phosphate. Data were expressed as the mean and standard error from three experiments. PolyP, polyphosphate. ${ }^{\text {aff }}$ Means with different superscripts differ $(p<0.05)$.

mation is available about catalytic properties of polyP degrading enzymes. Previous studies were focused on its hydrolysis of structurally-simple short and medium-chain polyP $[9,13]$.

The exopolyphosphatase activity of wheat phytase toward polyP is unusual in some aspects. Despite the fact that wheat phytase exhibits the highest activity toward phytate and $p$ NPP at acidic $\mathrm{pH}$ (4.5 to 5.0), it has no activity at $\mathrm{pH} 7.5$ [11], The exopolyphosphatase activity of this enzyme toward polyP75 and polyP1150 was observed at pH 5.2 and 7.5 (Figure 1). On the other hand, calf intestinal alkaline phosphatase previously known as a sole higher eukaryotic-derived enzyme with exopolyphosphatase activity could not degrade polyP15 or polyP75 at $\mathrm{pH}$ below 6.0 at all and $90 \%$ of its maximal activity was lost at $\mathrm{pH} 7$ to 7.5 [13]. Intriguingly, the catalytic action mode of exopolyphosphatases against polyP substrates at acidic and neutral $\mathrm{pH}$ may be different because numbers of Pi residues within substrates required for binding to the enzyme at acidic and neutral $\mathrm{pH}$ are 2 and 3, respectively [13]. In particular, wheat phytase was kinetically favorable in degrading longchain polyP because its overall catalytic efficiency $\left(\mathrm{V}_{\max } / \mathrm{K}_{\mathrm{m}}\right)$

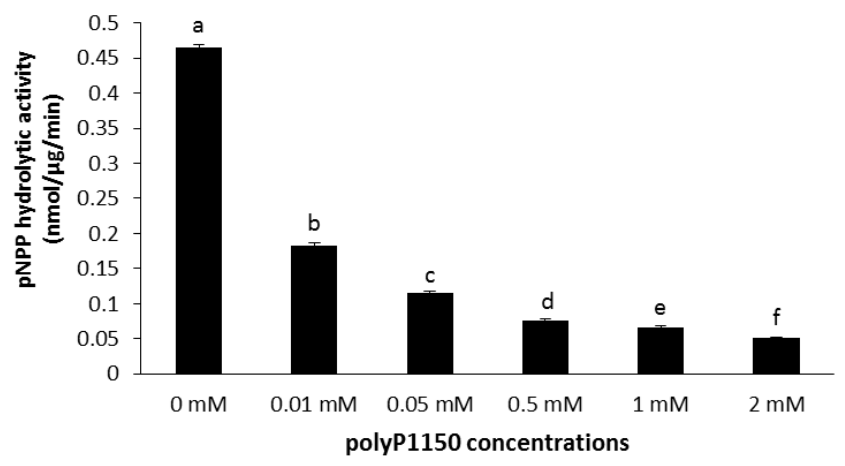

Figure 5. Effect of polyP1150 on monophosphate esterase activity of wheat phytase toward $p$-nitrophenyl phosphate. Data were expressed as the mean and standard error from three experiments. PolyP, polyphosphate. ${ }^{a-f}$ Means with different superscripts differ $(p<0.05)$. for polyP1150 was 1.46-fold higher than that for polyP75 (Table 1). However, values of $\mathrm{K}_{\mathrm{m}}$ and $\mathrm{V}_{\max }$ for polyP75 of wheat phytase were 100 -fold higher and 250 -fold lower, respectively, than those for polyP77 (almost identical to polyP75 in length) of calf intestinal alkaline phosphatase [13]. Thus, the kinetic performance for the exopolyphosphatase activity of wheat phytase toward medium-chain polyP seems to be poor. The exopolyphosphatase activity of wheat phytase toward polyP75 was almost unaffected by the presence of divalent metal ions such as $\mathrm{Mg}^{2+}, \mathrm{Ni}^{2+}, \mathrm{Co}^{2+}$, or $\mathrm{Mn}^{2+}$ (Figure 2). Its activity toward polyP1150 was inhibited by increasing the concentration of $\mathrm{Ni}^{2+}, \mathrm{Co}^{2+}$, and $\mathrm{Mg}^{2+}$ (Figure 3). Additionally, EDTA, a well-known metal remover, showed negligible effect on the exopolyphosphatase activity of wheat phytase (Figures 2, 3), suggesting that divalent metal ions could not act as cofactors for its catalytic activity. In previous studies, the exopolyphosphatase activity of inorganic pyrophosphatase from cattle tick, Rhipicephalus microplus, relied on $\mathrm{Mg}^{2+}$ [9] whereas activities of calf intestinal alkaline phosphatase and soluble pyrophosphatases from protozoa such as Trypanosoma brucei and Leishmania amazonesis required $\mathrm{Zn}^{2+}$ as cofactors [1315]. The monophosphate esterase activity of wheat phytase toward $p$ NPP was inhibited by the presence of polyP75 or polyP1150 in a dose-dependent manner (Figures 4, 5). Thus, it appears that the active site for polyP substrates of wheat phytase is consistent with that for $p$ NPP [13]. Similar observation was also made with calf intestinal alkaline phosphatase, displaying competitive inhibitory fashion of $p \mathrm{NPP}$-degrading activity by polyP [13].

So far, chickens have been regarded as the primary reservoir of Campylobacter jejuni and Salmonella typhimurium infection $[7,16]$. Moreover, long-chain polyP molecules like polyP1150 secreted by these enteric bacteria can aggravate inflammation in hosts such as human and bird [17], leading to intestinal mucosal damage, inflammatory diarrhea, and enteric fever [16,18]. Such situation can severely decrease the productivity of poultry industry and pose public health concern [7]. In conclusion, wheat phytase with an unexpected exopolyphosphatase activity has potential as a therapeutic tool and a next-generational feed additive for controlling long-chain polyP-induced inappropriate inflammation from Campylobacter jejuni and Salmonella typhimurium infection in public health and animal husbandry because wheat phytase is a relatively safe and endogenous strategy that can overcome drawbacks caused by resistance to antibiotics $[6,19]$ and prejudice and mistrust against the use of foreign microbial enzymes [20].

\section{CONFLICT OF INTEREST}

We certify that there is no conflict of interest with any financial organization regarding the material discussed in the manu- 
script.

\section{ACKNOWLEDGMENTS}

This research was supported by Basic Science Research Program through the National Research Foundation of Korea (NRF) funded by the Ministry of Education (2017R1D1A1B 03028091).

\section{REFERENCES}

1. Hassanian SM, Avan A, Ardeshirylajimi A. Inorganic polyphosphate: a key modulator of inflammation. J Thromb Haemost 2017;15:213-8. https://doi.org/10.1111/jth.13580

2. Morrissey JH, Choi SH, Smith SA. Polyphosphate: an ancient molecule that links platelets, coagulation, and inflammation. Blood 2012;119:5972-9. https://doi.org/10.1182/blood-201203-306605

3. Kumar A, Gangaiah D, Torrelles JB, Rajashekara G. Polyphosphate and associated enzymes as global regulators of stress response and virulence in Campylobacter jejuni. World J Gastroenterol 2016;22:7402-14. https://dx.doi.org/10.3748/wjg.v22. i33.7402

4. Varas MA, Riquelme-Barrios S, Valenzuela C, et al. Inorganic polyphosphate is essential for Salmonella typhimurium virulence and survival in Dictyostelium discoideum. Fron Cell Infect Microbiol 2018;8:8. https://doi.org/10.3389/fcimb.2018.00008

5. Awad WA, Dublecz F, Hess C, et al. Campylobacter jejuni colonization promotes the translocation of Escherichia coli to extra-intestinal organs and disturbs the short-chain fatty acids profiles in the chicken gut. Poult Sci 2016;95:2259-65. https://doi.org/10.3382/ps/pew151

6. Antunes P, Mourao J, Campos J, Peixe L. Salmonellosis: the role of poultry meat. Clin Microbiol Infect 2016;22:110-21. https://doi.org/10.1016/j.cmi.2015.12.004

7. Kassaify ZG, Mine Y. Nonimmunized egg yolk powder can suppress the colonization of Salmonella typhimurium, Escherichia coli O157:H7, and Campylobacter jejuni in laying hens. Poult Sci 2004;83:1497-506. https://doi.org/10.1093/ps/83.9. 1497

8. Doyle MP, Erickson MC. Reducing the carriage of foodborne pathogens in livestock and poultry. Poult Sci 2006;85:960-73. https://doi.org/10.1093/ps/85.6.960

9. Cruz CS, Costa EP, Machado JA, et al. A soluble inorganic pyrophosphatase from the cattle tick Rhipicephalus microplus capable of hydrolysing polyphosphates. Insect Mol Biol 2018; 27:260-7. https://doi.org/10.1111/imb.12369
10. Li YD, Awati A, Schulze H, Partridge G. Phytase in non-ruminant animal nutrition: a critical review on phytase activities in the gastrointestinal tract and influencing factors. J Sci Food Agric 2015;95:878-96. https://doi.org/10.1002/jsfa.6998

11. Dionisio G, Holm PB, Pedersen HB. Wheat (Triticum aestivum L.) and barley (Hordeum vulgare L.) multiple inositol polyphosphate phosphatases (MINPPs) are phytases expressed during grain filling and germination. Plant Biotechnol J 2007;5:32538. https://doi.org/10.1111/j.1467-7652.2007.00244.x

12. Kilaparty SP, Singh A, Baltosser WH, Ali N. Computational analysis reveals a successive adaptation of multiple inositol polyphosphate phosphatase 1 in higher organisms through evolution. Evol Bioinform Online 2014;10:239-50. https:// doi.org/10.4137/EBO.S18948

13. Lorenz B, Schroder HC. Mammalian intestinal alkaline phosphatase acts as highly active exopolyphosphatase. Biochim Biophys Acta 2001;1547:254-61. https://doi.org/10.1016/S01674838(01)00193-5

14. Lemercier G, Espiau B, Ruiz FA, et al. A pyrophosphatase regulating polyphosphate metabolism in acidocalcisomes is essential for Trypanosoma brucei virulence in mice. J Biol Chem 2004; 279:3420-5. https://doi.org/10.1074/jbc.M309974200

15. Espiau B, Lemercier G, Ambit A, et al. A soluble pyrophosphatase, a key enzyme for polyphosphate metabolism in Leishmania. J Biol Chem 2006;281:1516-23. https://doi.org/10.1074/ jbc.M506947200

16. Humphrey S, Chaloner G, Kemmett K, et al. Campylobacter jejuni is not merely a commensal in commercial broiler chickens and affects bird welfare. mBio 2014;5:e01364-14. https://doi. org/10.1128/mBio.01364-14

17. Dinarvand P, Hassanian SM, Qureshi SH, et al. Polyphosphate amplifies proinflammatory responses of nuclear proteins through interaction with receptor for advanced glycation end products and P2Y1 purinergic receptor. Blood 2014;123: 935-45. https://doi.org/10.1182/blood-2013-09-529602

18. Foley SL, Johnson TJ, Ricke SC, Nayak R, Danzeisen J. Salmonella pathogenicity and host adaptation in chicken-associated serovars. Microbiol Mol Biol Rev 2013;77:582-607. https:// doi.org/10.1128/MMBR.00015-13

19. Inglis GD, Morck DW, McAllister TA, et al. Temporal prevalence of antimicrobial resistance in Campylobacter spp. from beef cattle in Alberta feedlots. Appl Environ Microbiol 2006; 72:4088-95. https://doi.org/10.1128/AEM.02830-05

20. Chouchene A, Micard V, Lullien-Pellerin V. Evidence of a synergistic effect between pea seed and wheat grain endogenous phytase activities. J Agric Food Chem 2018;66:1203441. https://doi.org/10.1021/acs.jafc.8b03803 